\title{
Customizable and Optimized Drill Bits Bio-inspired from Wood-Wasp Ovipositor Morphology for Extraterrestrial Surfaces*
}

\author{
Mohamed G. Alkalla ${ }^{1,2}$, Yang Gao ${ }^{1}$, Arthur Bouton ${ }^{1}$
}

\begin{abstract}
As massive scientific information is trapped inside the geologic formation of planetary bodies, the objectives of most exploration missions mainly involve sampling, in-situ testing and analyzing of the cutting's formation for seeking any sign of primitive life or resources. This can be accomplished by subsurface exploration by specific drilling techniques which entail challenges that are apparently more complex than drilling on the earth. One of these challenges is the low-gravity that should be compensated by the over-head mass of the drilling system. This excessive mass represents a burden during launching the mission. Therefore, it is necessary to choose an energy efficient and light-weight drilling system capable of reaching high depths. This article focuses on optimizing drill bit geometry (i.e., profiles, cross-sections, and teeth) of the bio-inspired wood-wasp drill for targeting new potential depths into the Martian regolith and reducing its drilling time. Different morphological designs of the drill bit are generated and experimentally tested for their drilling feasibility into fine and coarse-grain Martian regolith. A Comparison between old and new proposed drill bits is presented, based on drilling time, consumed power, and slope of depth-time curve. The proposed designs show a significant reduction of the drilling time between $\mathbf{2 0} \%$ to $\mathbf{5 6 . 5} \%$ over the old one, while the required over-head mass $(\mathrm{OHM})$ and power to penetrate $760 \mathrm{~mm}$ depth is only $\mathbf{3} \mathrm{kg}$ and $\mathbf{4 5}$ watts, respectively. This practical work reveals the necessity of getting customizable drill bits for each single location of the extraterrestrial surfaces even on Moon or Mars based on its unique character which can be categorized as soft and hard formulations.
\end{abstract}

\section{INTRODUCTION}

Drilling systems have an increasing importance whether on earth or on planetary/extraterrestrial surfaces due to their critical role for extracting the soil properties, setting-up foundations for new inhabitation structures, and seeking either potential resources and biomarkers or historic and scientific information trapped beneath the surfaces. This importance is reflected in many publications and drilling or sample acquisition systems for extraterrestrial surfaces. The most common-used drilling systems are: rotary drills which use spiral teeth or flutes drill-bit rotated by powerful motors and backed with over-head weight for boosting the penetration, [1], [2], percussive drills which utilize continuous high frequency percussive (hammering) motion for breaking the rock formations [3], and rotary-percussive drills which combine the advantages of both systems as, ExoMars-rover

\footnotetext{
*This work is supported by grant EP/R026092 (FAIR-SPACE Hub) through UKRI under the Industry Strategic Challenge Fund (ISCF) for Robotics and AI Hubs in Extreme and Hazardous Environments.

1 FAIR-SPACE Hub, Surrey Space Centre, University of Surrey, 388 Stag Hill, Guildford, GU2 7XH, UK. https://www.fairspacehub.org/

2 Mohamed Alkalla, corresponding author, m.alkalla@surrey.ac.uk; On leave of Production Engineering \& Mechanical Design Dept., Mansoura University, Egypt, m_elkalla@mans.edu.eg.
}

drill, [4]. The rotary system has advantage of drilling into soft soil with high depths, however it suffers from excessive bit wear at high rotational speeds and requires high axial forces, hence, a high power supply an excessive over-headmass (OHM) are required. The percussive drill is widely used for penetrating brittle material (i.e., concreate and hard rock formations) and needs less OHM than the rotary one. However, penetration rate capability is low and has limited depth into the soft rock formations, besides the wellbore instability due to percussive action. The rotary-percussive systems are quite efficient but are heavy and power-hungry, [5]. Zacny et al, [5] have described the planetary drilling as; "The act of drilling a hole on a faraway planetary body is somewhat analogous to driving a planetary rover in complete darkness, with no view of the road ahead". Hence, the candidate drill system for such kind of missions should be high energy-efficient, practical, and has minimum weight to mitigate the whole exploration task duties. One of the recent drilling techniques that meets these criteria is the dual reciprocation drill DRD system which is inspired by drilling technique of wood wasp into the trees. This technique has been revealed and investigated by Surrey Space Centre in many publications, [6], [7]. The system is very efficient and light weight compared to other drilling systems.

\section{Dual Reciprocating DRILling (DRD) MECHANISM}

The wood-wasp unique technique of drilling has drawn the space researchers' attention more over than ten years ago to investigate its feasibility in engineering fields, particularly, on the extra-terrestrial surfaces. The wood-wasp has a very slender ovipositor compared to its length, though, it can efficiently drill deep holes into trees without being buckled or broken. Examples include, Sirex noctilio, as shown in Fig. 1, which has a $0.26 \mathrm{~mm}$ diameter and $10 \mathrm{~mm}$ length ovipositor and can sustain buckling load up to $0.25 \mathrm{~N}$, and M. n. nortoni which has a $0.218 \mathrm{~mm}$ diameter and $50 \mathrm{~mm}$ length and sustains buckling load of $0.0013 \mathrm{~N}$. This last one has a very flexible ovipositor; nevertheless, it uses a very unique and surprising technique for eliminating the bucking by using a groove on its abdomen equipped with clips as well as its legs as a guide for the ovipositor at earlier drilling stage of the ovipositor, in order to reduce the free length subjected to buckling, [8]. The drilling technique is based on generating a reciprocation motion of both valves of the ovipositor consisting of penetration (compression) and traction (tension) by cyclic motion of the wood-wasp 


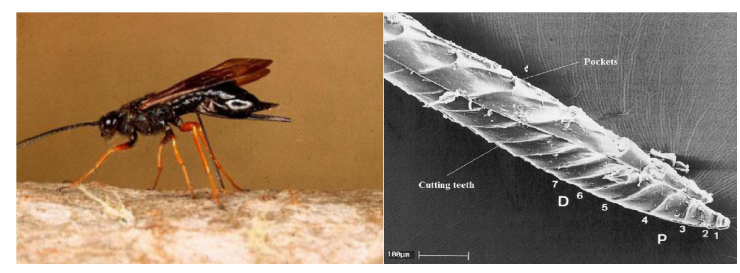

Fig. 1. Sirex noctilio, wood-wasp, left, (Credit: Neiker), microscopic view of ovipositor (right), [8].

abdomen muscles, in addition to applying an OHM by its body.

The paper presents a continuation of the previous work, presented in [7], [9], [10] in term of creating optimized and customizable drill bits for this dual reciprocating mechanism applicable for various extra-terrestrial surfaces. The previous research works have achieved a maximum depth of $760 \mathrm{~mm}$ with a fixed and bulky mechanism [9], [10], while the lately developed portable integrated design in [11] was limited to depth of $180 \mathrm{~mm}$ to avoid mechanism jamming and motor breaking down. The same fixed and bulky mechanism used in the previous researches is used in this study too, since it has the ability of extending the drilling depth by increasing the stem length. Its idea is a combination of crank-rocker mechanism and double crank-slider mechanism, since, one full cycle of the crank makes both drill-bit halves penetrate or retract respectively, as shown in Fig. 2.

\section{New Bio-Inspired Drill Bit Designs}

The various structures and morphologies of the woodwasp ovipositors presented in [8] and [12], have inspired this work to generate new nontraditional drill bits like the biomorphological ones. These ovipositors have complex profile shapes with spiral pockets to remove the cuttings and with gradually inclined teeth to break the wood tissues, as shown in Fig. 1. The new bit designs will be studied for their drilling capability, their convenience and feasibility with different regolith formations. Regolith itself is defined by the layer of granular material covering planetary bodies, and does not include the rocks and ice that may be found within these layers. It usually covers $1-2 m$ depth of most planetary surfaces. Mainly, two profiles are proposed from the observation

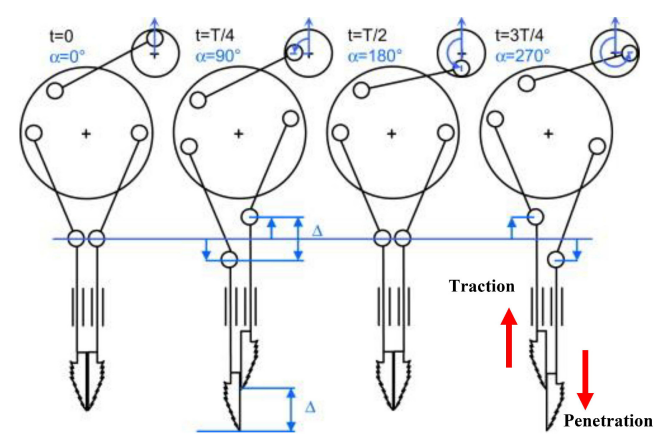

Fig. 2. Schematic diagram shows the principle of reciprocation of crankrocker-double crank-slider mechanism, [9].

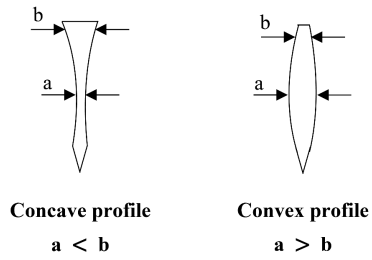

Fig. 3. Proposed surface profiles of the new DRD drill bits.

of the ovipositor microscopic images, in which simplified as concave and convex, as shown in Fig. 3. In addition, the helical teeth and two cross-section contours (i.e., circular and rhombic) are considered to investigate their impact on the drilling process. Therefore, a differentiation between these bio-morphological drill bit designs and the traditional one used previously in [9], [10] has to be performed. To establish a fair comparison throughout this study with the old design, the following aspects should be considered:

1) Drill bit no. 9 is chosen as the best candidate for this comparison, since it showed a significant performance into Martian regolith simulants SSC-1 and SSC-2 amongst all other bits in [10].

2) The same diameter of $20 \mathrm{~mm}$ is maintained for all bits at the largest cross section even at $a$ or $b$, as shown in Fig. 3.

3) The same length is used for all bits which is $160 \mathrm{~mm}$.

4) Same operational conditions are applied (e.g., frequency and amplitude of reciprocation, OHM, same set-up, simulant preparation, and lubrication of the sliders)

Six new drill bits are proposed, as shown in Fig. 4, and classified into four categories, as illustrated in Table I. The first category classifies the outer surface profile into cylindrical, concave and convex. The second one classifies the teeth angle measured perpendicular to the bit axis into straight $H=0^{\circ}$ or helical $H=20^{\circ}$. The third one classifies the cross-section contour into circular and rhombic/diamond. The fourth one classifies the bits based on the presence of teeth, since a hypothesis that the teeth may hinder the penetration into regolith is considered that worth to be

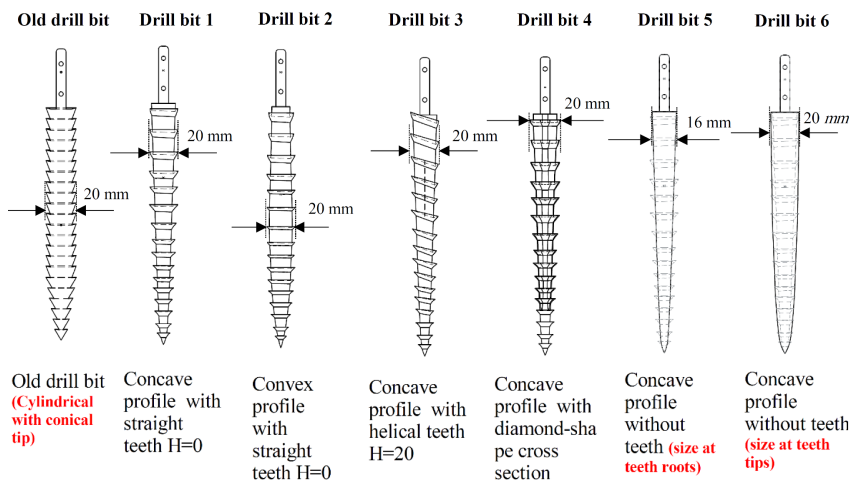

Fig. 4. The geometry (CAD models) of the old and new drill bits. 
TABLE I

ClASSIFICATIONS AND FEATURES OF THE DRILL BITS.

\begin{tabular}{lccccc}
\hline Drill bit & Surface profile & Teeth angle & C.S. contour & Teeth presence & One half bit volume, $\mathrm{x} 10^{3}\left(\mathrm{~mm}^{3}\right)$ \\
\hline Old bit & Cylindrical, conical tip & Straight, $\mathrm{H}=0^{\circ}$ & Circular & Yes & 15.75 \\
Bit no.1 & Concave & Straight, $\mathrm{H}=0^{\circ}$ & Circular & Yes & 9.65 \\
Bit no.2 & Convex & Straight, $\mathrm{H}=0^{\circ}$ & Circular & Yes & 11.63 \\
Bit no.3 & Concave & Helical Hax $=20^{\circ}$ & Circular & Yes & 9.32 \\
Bit no.4 & Concave & Straight, $\mathrm{H}=0^{\circ}$ & Rhombic & Yes & 7.891 \\
Bit no.5 & Concave & None & Circular & No & 8.50 \\
Bit no.6 & Concave & None & Circular & No & 15.26 \\
\hline
\end{tabular}

checked. The last column in the table represents total volume of single half of bit introducing a good idea about its mass. Proposed bit no. 5 is similar to bit no. 1 when teeth are removed which makes the outer size reduced to $16 \mathrm{~mm}$, while bit no. 6 outer profile is taken tangent to the teeth tips to maintain the same diameter of $20 \mathrm{~mm}$. both are kept in this study.

Drill bit 3 has gradual helical teeth like ovipositor teeth in Fig. 1, with a maximum helical angle of $20^{\circ}$. The microscopic view of the ovipositor shows an interlock or olistheter system of both ovipositor valves to keep them connected together, slide smoothly, and preserve the egg canal in the right place, [13]. An interlock system is added to this bit to avoid the lateral splitting due to the lateral forces on the helical teeth, as shown in Fig. 5. The drill bits are made of Carbon-Fibre Polylactic Acid (CF-PLA) which is stiffer than the traditional PLA and fabricated by the $3 \mathrm{D}$ printer to reduce the machining cost and time.
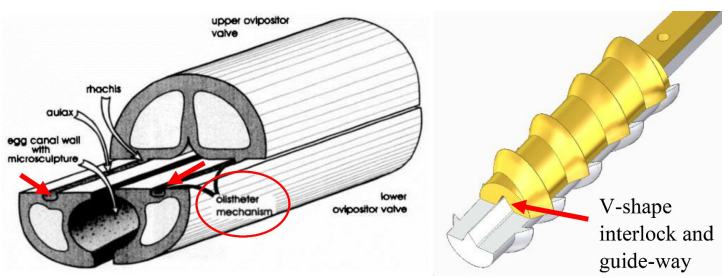

Fig. 5. Representation of ovipositor with valves differentially protruding with olistheter mechanism, [13], left. V-shape interlock and guide way for helical teeth drill bit no.3, right.

\section{TEST Rig AND EXPeriments SETUP}

The test rig consists mainly of three systems, see Fig. 6 . The first system is the mechanical system which comprises the dual reciprocating mechanism attached to a vertically sliding platform on two side rails, counter-mass for calibrating the OHM required for the system and keeping the mechanism on a standby after finishing the experiments, long stem connecting the drill bits with the mechanism. The second system is the electrical system which basically consists of adjustable power supply unit PSU, TTi EX4210R and Maxon 118776 DC motor (speed constant of 491 $\mathrm{rpm} / \mathrm{V}$ ) for driving the mechanism crank and coupled with Maxon gearbox GP42C with reduction ratio of 43:1. The third system is the data acquisition system which consists of two linear potentiometers (Spectra Symbol Softpot) with

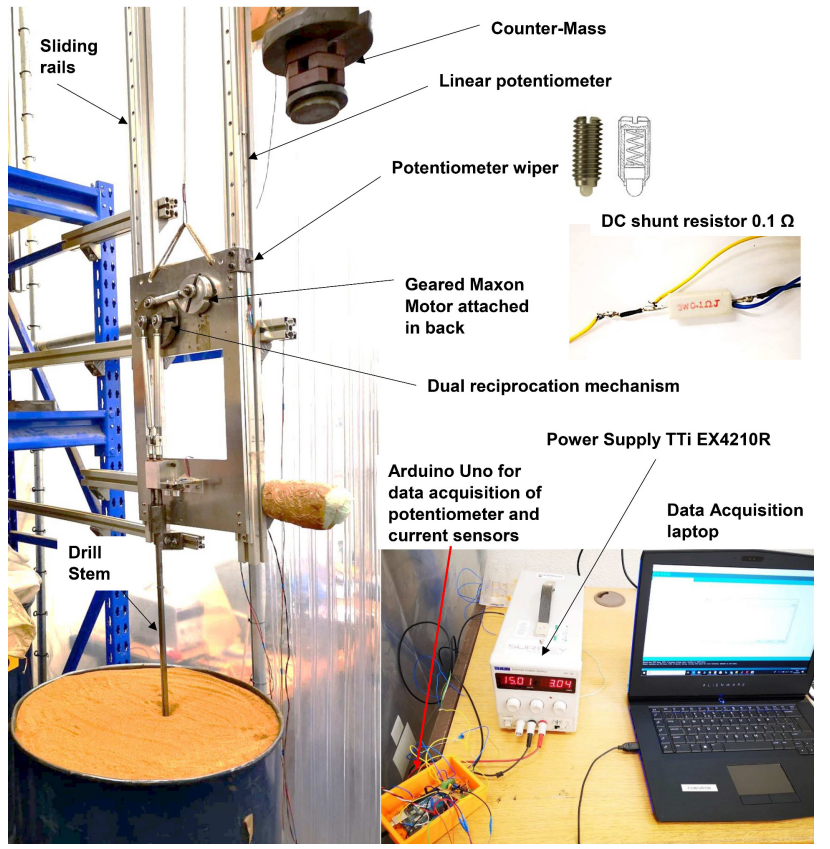

Fig. 6. Set-up of dual reciprocating drill mechanism modified test rig.

range of $500 \mathrm{~mm}$ attached in tandem on the mechanism side, DC shunt resistor $0.1 \Omega$ as current sensor, Arduino Uno board as a micro-controller and data acquisition unit for recording and plotting the readings by the serial port.

Two improvements are done for this rig: The pin with roller which was contacting the potentiometer in the old mechanism is replaced with an adjustable contact wiper which make the contact with the potentiometer easier and more accurate without any reading ripples or drop due to losing the contact. This is attributed to the axis of wiper which is perpendicular to the potentiometer and any vibration or lose of contact is compensated with the spring displacement. The second improvement is using single Arduino board instead of two in order to gain all sensor readings concurrently with the real time. The same operational conditions are applied for all the drill bits, as stated in Table II. By applying voltage of $15 \mathrm{~V}$, the DC geared motor rotates with an angular velocity of $171.27 \mathrm{rpm}$ (equivalent to $2.85 \mathrm{rps}(H Z)$ ) which is the same frequency of the reciprocation motion. The amplitude of displacement of each drill bit from the neutral position is adjusted to be $\pm 3 \mathrm{~mm}$ which represents $\Delta / 2$ in Fig. 2 . 
TABLE II

OPERATION CONDITIONS FOR DRILLING PROCESS

\begin{tabular}{lc}
\hline Operation parameters & Value \\
\hline Over-head mass (OHM) & $3 \mathrm{~kg}$ \\
Voltage & $15 \mathrm{~V}$ \\
Current limit & $5 \mathrm{~A}$ \\
Reciprocation Amplitude & $3 \mathrm{~mm}$ \\
Reciprocation frequency & $2.8 \mathrm{~Hz}$ \\
\hline
\end{tabular}

\section{EXPERIMENTAL RESULTS}

The type of formation, its hardness and abrasiveness dictate the method of excavation, cutter tooth material and bit geometry. Planetary media includes rocks, ice, permafrost and regolith, which are distinguished by their hardness, level of consolidation and characteristics dependent on factors such as gravity, temperature and pressure, [5]. Two distinct types of Martian regolith simulants are used for these experiments. The first one is the Engineering Soil Simulant, ES-3, [14], which is developed and used for testing the ExoMars rover. It is a coarse silica sand (quartz) with sub-rounded grains and particle size of 400-1000 $\mu \mathrm{m}$. The other simulant is Surrey Space Centre Mars Simulant 2, SSC-2, [15], which is a crushed-garnet-based sand and considered the finest and densest simulant amongst others in the Surrey Space Centre with size of 30-90 $\mu \mathrm{m}$, see Fig. 7. It was made intentionally for locomotion and drilling systems testing.

A drum with approximately $600 \mathrm{~mm}$ diameter and 800 $\mathrm{mm}$ height is used for containing the regolith during the experiments. A depth of $760 \mathrm{~mm}$ is set for all experiments with a mechanical stop to refrain the mechanism from hitting the drum bottom. Each drill bit is tested at least four runs to guarantee the accurate performance of the drilling by getting the average value. All drill bits have proved their capability of drilling this depth, the average time elapsed for drilling this depth is recorded for each run and get the average result, as shown in Fig. 8. At first glance, it is noticed that all drill bits reach the maximum depth into ES-3 in shorter time than they do into SSC -2 . The second notice obtained from the readings is that most proposed bits have reduced the drilling time, and this is reflected significantly in Table III which illustrates the reduction ratio of drilling time for the new bits

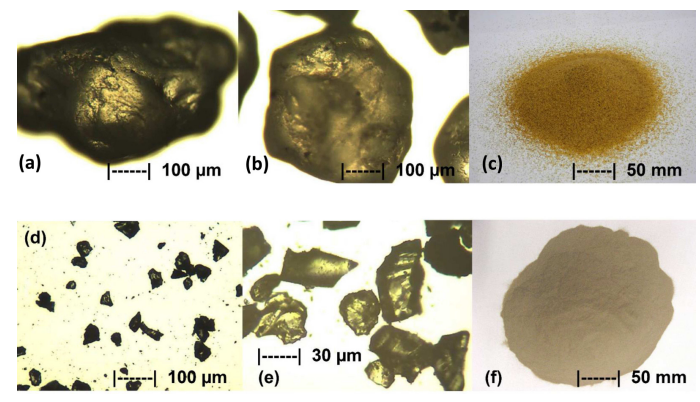

Fig. 7. Martian Simulant ES-3 (a, b, c) and SSC-2 (d, e, f) photos taken by optic microscope and digital camera, [15], [16].

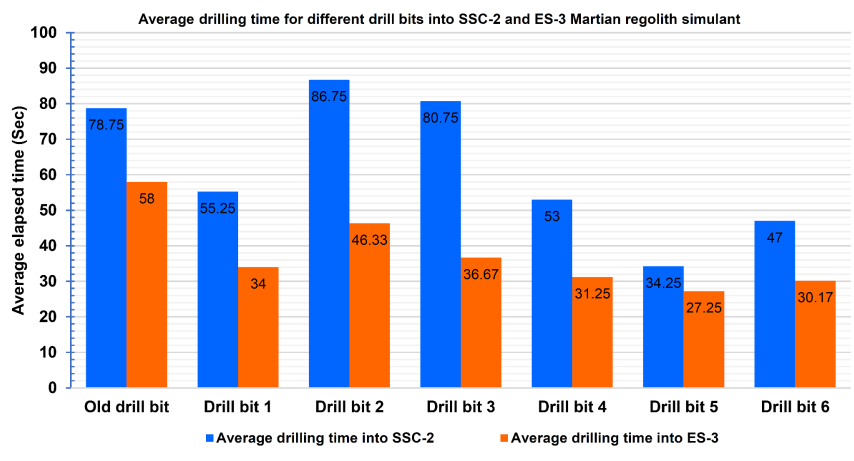

Fig. 8. Average time for drilling $760 \mathrm{~mm}$-depth into SSC-2 and ES-3 Martian regolith simulants for different drill bits.

TABLE III

DRILLING TIME REDUCTION PERCENT OF NEW BITS w.r.t. OLD BIT

\begin{tabular}{|c||c|c|}
\hline Drill Bit no. & SSC-2 \% & ES-3 \% \\
\hline 1 & 29.8 & 41.4 \\
2 & - & 20.1 \\
3 & - & 36.8 \\
4 & 32.7 & 46.1 \\
5 & 56.5 & 53 \\
6 & 40.3 & 48 \\
\hline
\end{tabular}

with respect to the old one. Bit no. 1 with concave profile has an excellent result than bit no. 2 with convex profile, however the bio-morphology of Sirix Nuctilio ovipositor is convex. The convex and helical teeth features (Bit 2 and 3) do not present a significant improvement of drilling into SSC-2, while have good results into ES-3. This reveals that it has more traction over penetration capability, and this features are useful with hard formation not the soft one. Since these features are powerful for removing cutting, its role with the soft regolith is insignificant. Further discussion on these results will be presented in section VI.

\section{A. Drilling Depth versus Time}

Studying the drilling curves is very important and gives a good indication not only for the performance of these bits during the entire drilling process, but also for potential depths which could be reached in the future. Consequently, a good prediction of the potential depths should be made based on the slope or gradient of these curves. Figure $9 a$ and $9 b$ show the depth curves versus time for all drill bits into both regoliths. The closest curve to the average among all runs is chosen to be plotted. The curves can be divided into three interesting parts classified as: initial penetration, low-level depth, and high-level depth. The first one is obtained due to the effect of OHM just after releasing the mechanism. For example, the drill bit 5 and 6 have initial depth into ES-3 about $320 \mathrm{~mm}$ and $200 \mathrm{~mm}$ while the old bit has $160 \mathrm{~mm}$. This initial depth is gained without applying any actuation forces or consuming any power. The second part to be studied is the low-level depth up to $500 \mathrm{~mm}$, it seems that the slope of all bits is close/converge to each other. The last part is beneficial for studying the trend of the curve over 


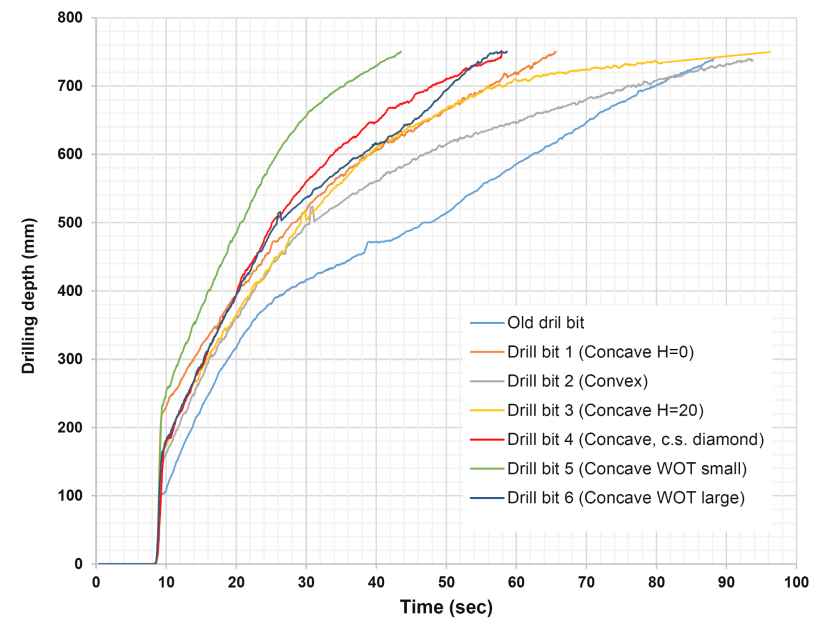

(a)

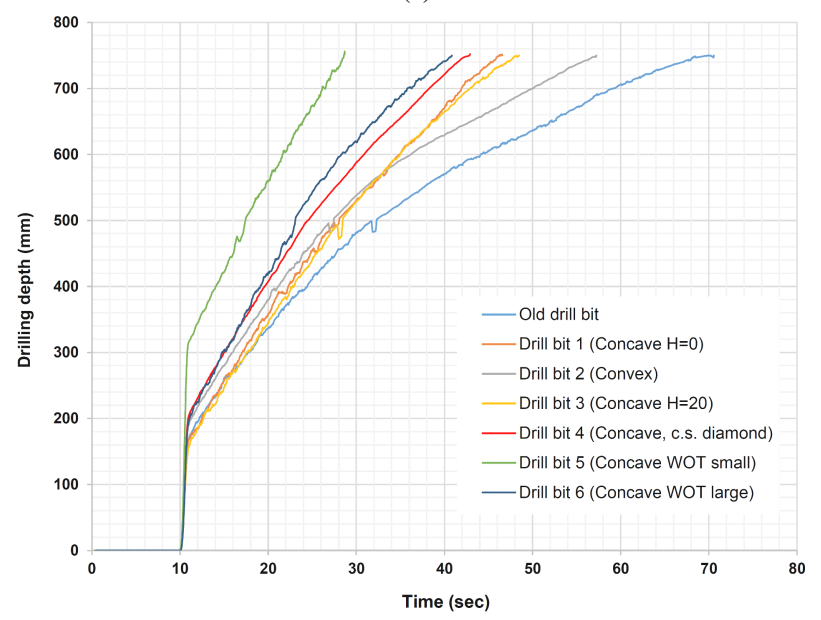

(b)

Fig. 9. Drilling depth vs. time for different drill bits into (a) SSC-2 and (b) ES-3.

$500 \mathrm{~mm}$ depth which greatly diverge from each other. This is helpful for choosing the most convenient bit for targeting very high depth. Based on the gradient and tangent lines for this portion and by extending this curve with estimation error of $10-20 \%$, it is easy to predict the behavior of the curves and estimated depth over 300 second. This result is stated in Table IV.

TABLE IV

PREDICTED DEPTH $(\mathrm{mm})$ INTO SSC-2 AND ES-3 AT 300 SEC.

\begin{tabular}{lccccccc}
\hline Drill bit & Old & no. 1 & no. 2 & no. 3 & no. 4 & no. 5 & no. 6 \\
\hline SSC-2 & 1350 & 1600 & 1100 & 1000 & 1400 & 1700 & 1500 \\
ES-3 & 1400 & 2200 & 1700 & 1900 & 2500 & 2600 & 2200 \\
\hline
\end{tabular}

\section{B. Consumed Power of Drill Bits}

It is necessary to examine the current readings to get an adequate idea about the power consumption by each drill bit. Measured current data are filtered and plotted in Fig. 10a and Fig. 10b. They show that at the ideal/non-drilling period the

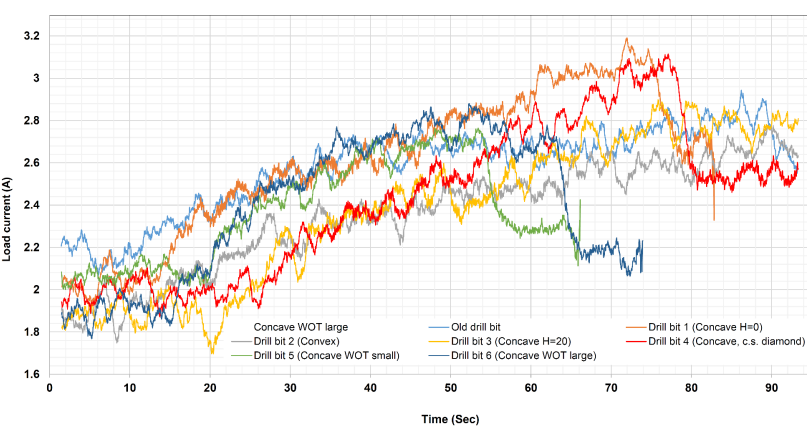

(a)

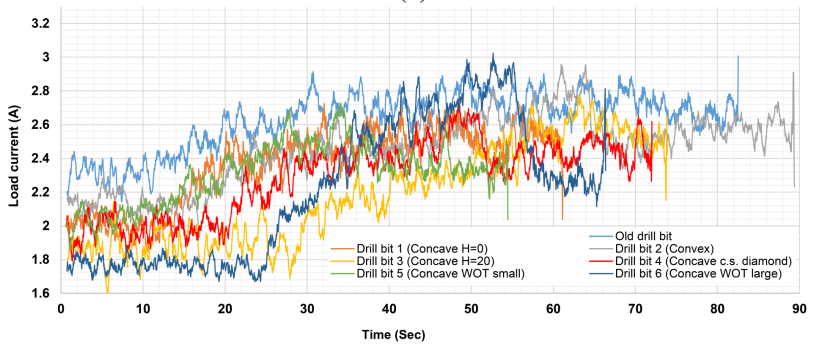

(b)

Fig. 10. Filtered current (Ampere) reading for different drill bits into (a) SSC-2 and (b) ES-3.

initial current is approximately around $2 A$. When the drilling starts the current begin to increase to 2.5 or $3 A$ in most cases. The consumed current during drilling is just about $1 A$, while the current dissipated internally in the system is about $2 A$ due to the joints friction and bearings wear, where this mechanism has been using over many years. The maximum mean and peak current into both SSC-2 and ES-3, as well as, the maximum consumed power based on the maximum current for all drill bits are illustrated in Table V.

\section{DISCUSSIONS \& CONCLUSIONS}

The capabilities of the drill bit designs with different morphological features should be throughly discussed in the light of results of the elapsed time, depth-time curves, and current readings. They can be summarized in the following points:

- The concave profile is very efficient for drilling into both simulants than both cylindrical and convex profiles. This is due to its penetration capability which is most required with soft regolith than the traction capability.

- The convex profile and helical teeth show a significant performance when transit from fine to coarse-grain regolith. It is believed that this kind of bits can be well-fitted for hard formations, like the wasp ovipositor into the hard tissue of the trees. This is attributed to its traction and cutting removal capabilities over the penetration one.

- The role of helical teeth is to remove the cutting outside the hole bore easily. In case of fine-grain regolith, such as SSC-2, the necessity of removing the cutting is not applicable due to its mechanical properties (grain size) which makes it like a high-viscous fluid seeping 
TABLE V

THE MAXIMUM CURRENT (FILTERED AND UNFILTERED) AND MAXIMUM POWER CONSUMPTION FOR DRILL BITS.

\begin{tabular}{ccccccc}
\hline Drill bit & \multicolumn{2}{c}{$\begin{array}{c}\text { Maximum current into SSC-2 }(A) \\
\text { Mean (filtered) }\end{array}$} & $\begin{array}{c}\text { Maximum current into ES-3 }(A) \\
\text { Instant Peak (ripples) }\end{array}$ & $\begin{array}{c}\text { Mean (filtered) } \\
\text { Instant Peak (ripples) }\end{array}$ & $\begin{array}{c}\text { Maximstantly } \\
\text { power }(w a t t s)\end{array}$ & $\begin{array}{c}\text { Maximum average } \\
\text { power }(w a t t s)\end{array}$ \\
\hline Old bit & 2.96 & 3.88 & 3.05 & 59.655 & 59.655 & 45.75 \\
Bit no. 1 & 3.2 & 4.365 & 2.75 & 65.475 & 65.475 & 48 \\
Bit no. 2 & 2.98 & 3.977 & 2.97 & 59.655 & 59.655 & 44.7 \\
Bit no. 3 & 2.9 & 4.365 & 2.8 & 65.475 & 65.475 & 43.5 \\
Bit no. 4 & 3.12 & 4.656 & 2.75 & 69.84 & 69.84 & 46.8 \\
Bit no. 5 & 2.76 & 4.171 & 2.73 & 62.565 & 62.565 & 41.4 \\
Bit no. 6 & 2.88 & 4.171 & 3.05 & 66.93 & 66.93 & 45.75 \\
\hline
\end{tabular}

easily to fill any cavity again. In this case, the teeth present a burden because of carrying permanently fine particles on them instead of removing these particles outside. This is apparently reflected in the readings of mean current into SSC-2 which show that the consumed current is the least with non-teethed drill bit 5 and 6 .

- Obviously, the rhombic-cross-section feature reduces the elapsed time of drilling, since it reduces the crosssection area subjected to regolith pressure.

- Customizable drill bits can be obtained from this study with respect to the area/region of the extraterrestrial surface required to be drilled, as given in Table VI. Therefore, the best expected and candidate drill bits for hard formations and icy-regolith in the permanently shadowed craters near the Lunar South Pole or the duricrust on Mars should be the convex then concave (both with diamond c.s. and helical teeth) which will be extensively investigated in the future work.

- A striking notice non-intentionally occurred during an individual run when the mechanism-slider was very loose which let the mechanism vibrated during drilling. It is found that this run with vibration took half duration of normal runs. Although, this run was rejected, since the operational conditions have changed and this could affect the fairness of comparison, it triggered the idea of combining the vibration with reciprocation motion in future work. Also, the tribological properties and wear mechanism between the drill and regolith are very important and are going to be studied in the future work.

TABLE VI

EVALUATION OF DRILL BIT FEATURES W.R.T. FINE, COARSE, AND POTENTIAL ICY REGOLITH $(+++$ OUTSTANDING, ++ EXCELLENT, + GOOD, O FAIR, - NOT GOOD, - - BAD).

\begin{tabular}{lccc}
\hline Design Features & $\begin{array}{c}\text { Fine grains } \\
\text { regolith }\end{array}$ & $\begin{array}{c}\text { Coarse grain } \\
\text { regolith }\end{array}$ & $\begin{array}{c}\text { Potential Icy } \\
\text { regolith }\end{array}$ \\
\hline Cylindrical profile & o & - & -- \\
Concave profile & + & ++ & ++ \\
Convex profile & -- & + & ++ \\
Circular C.S. & o & o & o \\
Diamond C.S. & + & ++ & +++ \\
Helical teeth & -- & ++ & +++ \\
Without teeth & +++ & + & - \\
\hline
\end{tabular}

\section{REFERENCES}

[1] M. Badescu, Y. Bar-Cohen, S. Sherrit, X. Bao, Z. Chang, C. Donnelly, and J. Aldrich, "Percussive augmenter of rotary drills (parod)," in Sensors and Smart Structures Technologies for Civil, Mechanical, and Aerospace Systems 2012, vol. 8345. International Society for Optics and Photonics, 2012, p. 83450J.

[2] K. Zacny, G. Paulsen, and M. Szczesiak, "Challenges and methods of drilling on the moon and mars," in 2011 Aerospace Conference. IEEE, 2011, pp. 1-9.

[3] J. Grygorczuk and Ł. Wisniewski, "Hammering mechanism for hp3 experiment (insight)," in Proceedings of the 43rd Aerospace Mechanisms Symposium, 2016, pp. 415-428.

[4] P. Magnani, E. Re, A. Fumagalli, S. Senese, G. Ori, A. Gily, and P. Baglioni, "Testing of exomars em drill tool in mars analogous materials," Proceedings Advanced Space Technologies for Robotics and Automation (ASTRA). Noordwijk, The Netherlands: European Space Agency, 2011.

[5] K. Zacny, Y. Bar-Cohen, M. Brennan, G. Briggs, G. Cooper, K. Davis, B. Dolgin, D. Glaser, B. Glass, S. Gorevan, et al., "Drilling systems for extraterrestrial subsurface exploration," Astrobiology, vol. 8, no. 3, pp. 665-706, 2008

[6] Y. Gao, A. Ellery, M. Jaddou, and J. Vincent, "Deployable wood wasp drill for planetary subsurface sampling," in 2006 IEEE Aerospace Conference. IEEE, 2005, pp. 8-pp.

[7] Y. Gao, A. Ellery, M. Sweeting, and J. Vincent, "Bioinspired drill for planetary sampling: literature survey, conceptual design, and feasibility study," Journal of spacecraft and rockets, vol. 44, no. 3, pp. 703-709, 2007.

[8] J. Vincent and M. King, "The mechanism of drilling by wood wasp ovipositors," Biomimetics (USA), 1995.

[9] T. P. Gouache, Y. Gao, P. Coste, and Y. Gourinat, "First experimental investigation of dual-reciprocating drilling in planetary regoliths: Proposition of penetration mechanics," Planetary and Space Science, vol. 59, no. 13, pp. 1529-1541, 2011.

[10] C. Pitcher and Y. Gao, "Analysis of drill head designs for dualreciprocating drilling technique in planetary regoliths," Advances in Space Research, vol. 56, no. 8, pp. 1765-1776, 2015.

[11] C. Pitchr and Y. Gao, "First implementation of burrowing motions in dual-reciprocating drilling using an integrated actuation mechanism," Advances in Space Research, vol. 59, no. 5, pp. 1368 - 1380, 2017. [Online]. Available: http://www.sciencedirect.com/science/article/pii/S0273117716307219

[12] D. Quicke, A. LeRalec, and L. Vilhelmsen, "Ovipositor structure and function in the parasitic hymenoptera." Rendiconti, no. 47, pp. 197239, 1999.

[13] M. H. Rahman, M. G. Fitton, and D. L. Quicke, "Ovipositor internal microsculpture in the braconidae (insecta, hymenoptera)," Zoologica Scripta, vol. 27, no. 4, pp. 319-332, 1998.

[14] T. P. Gouache, N. Patel, C. Brunskill, G. P. Scott, C. M. Saaj, M. Matthews, and L. Cui, "Soil simulant sourcing for the exomars rover testbed," Planetary and Space Science, vol. 59, no. 8, pp. 779787, 2011.

[15] G. Scott and C. Saaj, "Measuring and simulating the effect of variations in soil properties on microrover trafficability," in AIAA SPACE 2009 Conference \& Exposition, 2009, p. 6468.

[16] T. Gouache, "Dual reciprocating drilling in planetary regoliths: evolution of a bio-inspired solution," Ph.D. dissertation, University of Surrey, 2011. 